\title{
Correlation of Processing, Inner Structure, and Part Properties of Injection Moulded Thin-Wall Parts on Example of Polyamide 66
}

\author{
Dietmar Drummer and Steve Meister \\ Institute of Polymer Technology, University Erlangen-Nuernberg, Am Weichselgarten 9, 91058 Erlangen, Germany \\ Correspondence should be addressed to Steve Meister; meister@lkt.uni-erlangen.de
}

Received 2 September 2014; Revised 26 November 2014; Accepted 30 November 2014; Published 21 December 2014

Academic Editor: Jan-Chan Huang

Copyright (C) 2014 D. Drummer and S. Meister. This is an open access article distributed under the Creative Commons Attribution License, which permits unrestricted use, distribution, and reproduction in any medium, provided the original work is properly cited.

\begin{abstract}
In micro- and thin-wall injection moulding the process conditions affect the developed internal structures and thus the resulting part properties. This paper investigates exemplarily on polyamide 66 the interactions of different cooling conditions on the morphological and crystalline structures. The investigations reveal that a slow cooling rate of the melt results in a homogeneous morphology and a higher degree of crystallinity and also a favoured crystalline structure. Consequently, the dielectric behaviour and light transmitting part properties are affected.
\end{abstract}

\section{Introduction}

Microsystems technology is reputed as a prospective key technology. The primary areas of application for polymer microparts are found in medical technology or biotechnology, as components of optical systems, microgears in microfluidics, as electronics, and microelectromechanical systems $[1,2]$. Due to increasing requirements for these microcomponents, a rise in the demand for higher part quality and the reproducibility simultaneously occurs [3].

A reduction in part dimensions causes an increase in cooling that affects its morphological and mechanical properties [4-7]. Furthermore, long-term properties can also be affected [8-10]. To counteract this, new technologies and processing strategies have been developed. For example, a slow cooling of the melt using low conductive mould materials or a dynamic temperature control of the cavity can be executed [11-15]. A transfer of the mechanical material properties in microparts, determined and validated on standardized test specimens, is only partially possible [16, 17]. Consequently, it is necessary to investigate the effects of part dimensions on the usable material properties [18-20].

In addition to the influence on the degree of crystallinity, the formation of crystalline structures is also affected by the process conditions. For example, polyamide 66 shows a polymorphic structure with two known stable crystal structures. These are denoted as $\alpha$ and $\gamma[21,22]$. The $\alpha$ crystals are favoured by annealing or crystallization at higher temperatures whereas the $\gamma$ crystals can be obtained at lower temperatures [21, 23]. According to Radusch et al. [24] the $\alpha$ crystals are more stable due to a better crystal perfection, whereas the $\gamma$ structure can be transformed into the $\alpha$ by thermal treatment. Furthermore, Kolesov et al. [25] have shown that for polyamide 6 mechanical properties, for example, stiffness, increase with higher fraction of $\alpha$ crystals. The different crystalline forms can be detected amongst other technologies with DSC measurements $[26,27]$ and smallangle (SAXS) and wide-angle X-ray scatterings (WAXS) [24, $26,28]$ or infrared spectroscopy $[21,25,29]$.

Furthermore, the internal structure of a polymer part affects the dielectric behaviour and was described for varied polymers [30-34]. In the case of polyamide 66 there are three relaxation peaks known [21]. These are labelled generally as $\alpha, \beta$, and $\gamma$ relaxations which are occurring at temperatures of $50^{\circ} \mathrm{C},-80^{\circ} \mathrm{C}$, and $-140^{\circ} \mathrm{C}$. Nuriel et al. [35] have shown that for higher crystalline polyamide 66 the relaxation shifts to a higher temperature. This correlates with an increasing 
TABLE 1: Material properties (manufacturer's data).

\begin{tabular}{lc}
\hline Parameter & PA66 Ultramid A3K \\
\hline Density $(\rho)\left(\mathrm{kg} \cdot \mathrm{m}^{-3}\right)$ & 1130 \\
Melting temperature $\left({ }^{\circ} \mathrm{C}\right)$ & 260 \\
Crystallization temperature $\left({ }^{\circ} \mathrm{C}\right)$ & 236 \\
\hline
\end{tabular}

activation energy for the relaxation process, which affects significantly the $\alpha$ relaxation.

The cooling conditions affect, besides the mechanical properties, the optical part properties [36]. As shown by Kolesov et al. [25] a faster cooling leads to a higher light transmission, especially at a lower wavelength. This effect is due to the crucial effect of spherulite size in comparison to the size of lamella on the light scattering and transparency. Similar effects are described for the semicrystalline materials $\mathrm{PE}$ and PP [37, 38].

However, a general representation of the interactions between the process conditions, the formation of internal structures, and the resulting part properties has not been done yet. Problems can be found in the modeling and understanding of the process, the investigation of internal structures into detail, or the influences on the part properties [4]. The aim of this paper is to correlate different process conditions (i.e., modified cooling conditions) with the resulting internal structures and the effect on part properties.

\section{Materials and Methods}

2.1. Material. The used material was a semicrystalline polyamide 66 (PA66) Ultramid A3K manufactured by BASF $\mathrm{SE}$. The material was chosen because of its good flow properties and its relevance for the production of common microand thin-wall parts. Characteristic values of the material are shown in Table 1.

2.2. Specimen and Processing. To investigate the effects of process conditions on the internal part properties a plate with a square-based shape with a length of $35 \mathrm{~mm}$ and a thickness of $0.5 \mathrm{~mm}$ was used (Figure 1). For injection moulding an Arburg Allrounder 370 U 700-30/30 injection moulding machine is utilized, equipped with a positioncontrolled screw with a diameter of $15 \mathrm{~mm}$. To achieve a dynamic mould temperature a variotherm temperature control system (type: SWTS 200, Single Temperiertechnik $\mathrm{GmbH}$ ) is used. The system employs water as the circulating fluid and has a heating and cooling circuit-switching device. The heating circuit allows for a fluid temperature of up to $200^{\circ} \mathrm{C}$. The master mould is maintained at a constant temperature for the purpose of processing stability, and only the temperature of the cavity inserts is actively controlled. This mould technology and the implemented dynamic mould tempering process allow for a significant variation of the part's morphology and crystalline structure. These cavity inserts were built-up layer by layer from a steel powder using a rapid tooling process (LaserCusing, Concept Laser $\mathrm{GmbH}$ ). This manufacturing process allows for a complex design of cooling

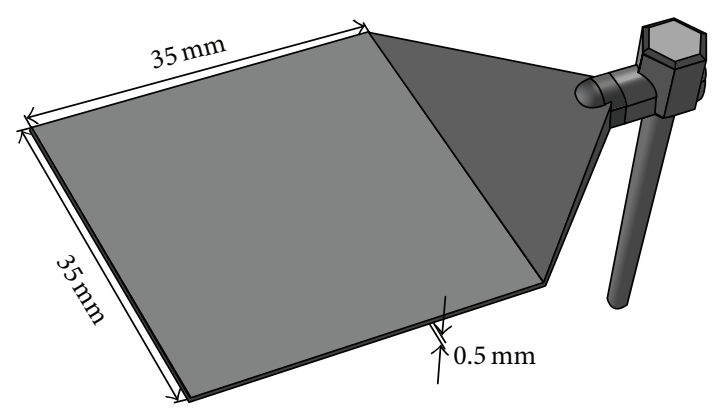

FIGURE 1: Geometry of the used plate specimen.

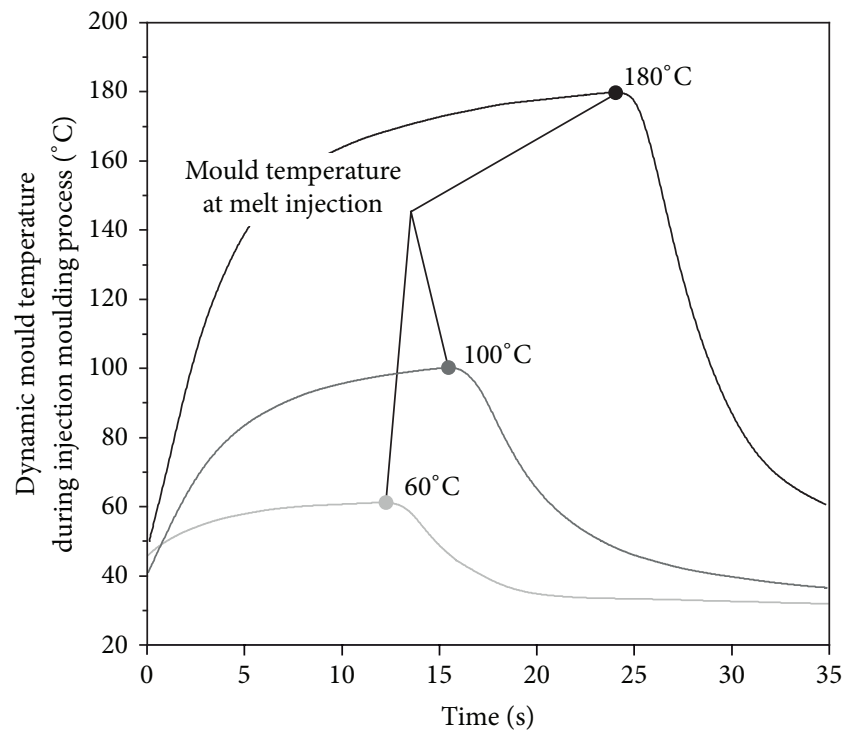

FIGURE 2: Mould temperatures during the injection moulding process to achieve varied morphology in the specimens (close-tocavity measurement).

channels (less than $2 \mathrm{~mm}$ behind the cavity surface) while also ensuring an optimized tempering of the cavity.

The combinations of insulation from the master mould and conformal cooling channels are conducive to particularly rapid temperature changes in the cavity. This allows a mould temperature during injection moulding to affect significantly the morphology development in the microspecimens. For this three different mould temperatures were selected: the minimal and maximal temperature to realize a reproducible process and a middle temperature according to standard process conditions. The mould temperature is measured by temperature sensors near the cavity. The curves of the temperature for the different mould temperatures during injection are shown in Figure 2. The mould temperature is highlighted when the melt is injected in the defined tempered mould. After injection the mould is cooled down for safe ejection of part and runner. Relevant processing conditions for the materials are shown in Table 2. 


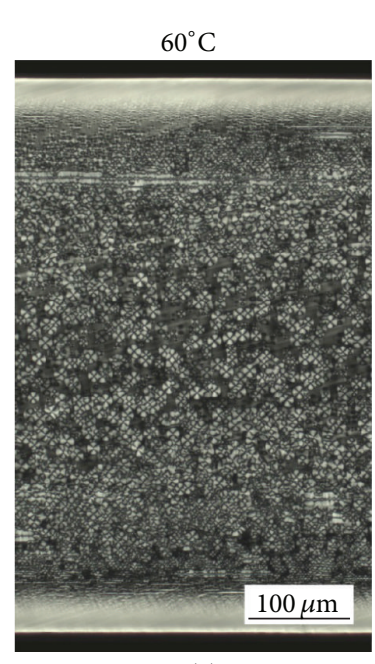

(a)

Mould temperature during injection

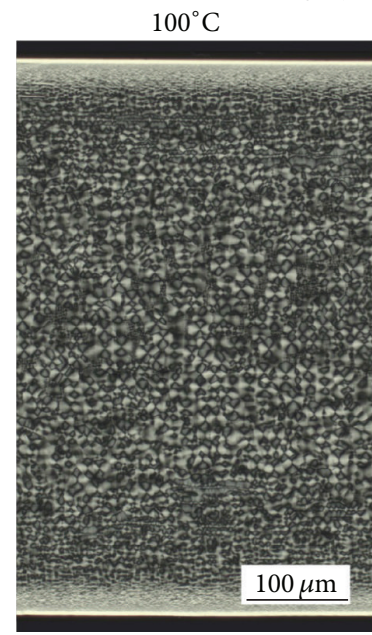

(b)

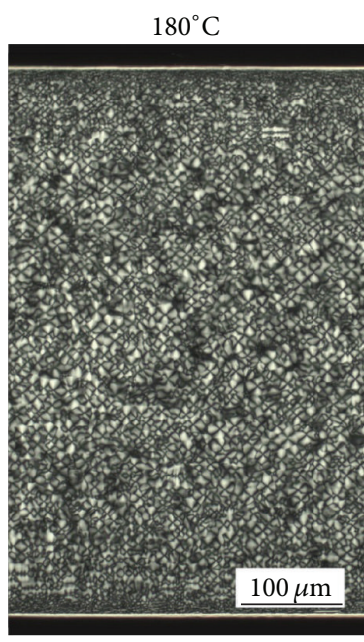

(c)

Figure 3: Morphology in dependence of process conditions.

TABle 2: Processing parameters.

\begin{tabular}{lccc}
\hline Material & $\begin{array}{c}\text { Melt } \\
\text { temperature } \\
{\left[{ }^{\circ} \mathrm{C}\right]}\end{array}$ & $\begin{array}{c}\text { Mould } \\
\text { temperature } \\
\text { during injection } \\
{\left[{ }^{\circ} \mathrm{C}\right]}\end{array}$ & $\begin{array}{c}\text { Melt flow } \\
\text { velocity } \\
{\left[\mathrm{cm}^{3} \mathrm{~s}^{-1}\right]}\end{array}$ \\
\hline PA 66 & 290 & $60 / 100 / 180^{1}$ & 18 \\
\hline
\end{tabular}

${ }^{1}$ See also Figure 2.

\subsection{Characterization}

2.3.1. Morphology and Crystallinity. The crystalline morphology was investigated on $10 \mu \mathrm{m}$ thick cuts using polarised light microscopy. These cuts were taken out from the middle of the specimen along the injection direction.

For crystallinity characterisation, infrared microscopy (Advantage, Spectra Tech Inc., Shelton, CT, USA) was applied. Three transmission measurements of thin cuts were carried out on each part. The ratio $r$ of extinction of the absorbance bands at $1199 \mathrm{~cm}^{-1}$ for the crystalline part and of $1180 \mathrm{~cm}^{-1}$ for the amorphous part describes the degree of crystallinity, as shown by Kohan [21]. The ratio $r$ allows for an approximate calculation of the degree of crystallization with the following equation [39]:

$$
f(r)=-1.30591+20.0028 r-1.86991 r^{2} .
$$

Furthermore, the two important crystalline modifications for the PA66, the $\alpha$ and the $\gamma$ modifications, can be characterized by the extinction of typical absorbance bands. The band at a wavelength of $1417 \mathrm{~cm}^{-1}$ is typical for the $\alpha$ modification, whereas the $\gamma$ modification affects the $1438 \mathrm{~cm}^{-1}$ band $[21,29]$. To compare the relative amount of the different crystalline structures the ratios of these bands $1417 \mathrm{~cm}^{-1} / 1438 \mathrm{~cm}^{-1}$ are used, the so-called polymorphyratio. An increasing value describes a higher fraction of $\alpha$ and correlates with a slower cooling rate of the material.
2.3.2. Dielectric Behaviour. For dielectric thermal analysis (DETA) a circular blank with a diameter of $25 \mathrm{~mm}$ was taken out of the specimens. These blanks were characterized using a dynamic mechanical analyzer (DMA; RSA-G2, TA Instruments) with a DETA measuring system Agilent 4294. Before testing the specimens were dry conditioned. The DETA was carried out at four frequencies of $2 \times 10^{3}$ to $2 \times 10^{6} \mathrm{~Hz}$ between a temperature sweep of 20 and $120^{\circ} \mathrm{C}$ (heating rate $2 \mathrm{~K} \mathrm{~min}^{-1}$ ). The DETA measurement allows the characterization of the reversible stored energy $\varepsilon^{\prime}$ in the material and the proportional dissipated energy $\varepsilon^{\prime \prime}$. These values are used to calculate the dissipation factor $\tan \delta$ according to

$$
\tan \delta=\frac{\varepsilon^{\prime \prime}}{\varepsilon^{\prime}} .
$$

The dissipation factor $\tan \delta$ is often used and evaluated in technical applications of dielectric relaxation spectroscopy, especially for electrotechnical characterization of a material. Besides, in contrast to the local-resolved FTIR analysis by means of the DETA measurements only integral properties can be characterized that means layer dependent properties cannot be detected.

2.3.3. Translucence. The translucence of the specimens was analyzed with an UV/VIS spectrometer Lambda 18 (Perkin Elmer Inc.). Therefore, the transmission of the light through the specimens was measured at a wavelength of $250-850 \mathrm{~nm}$ (visible range ca. $380-780 \mathrm{~nm}$ ).

\section{Results and Discussion}

3.1. Morphology. The process conditions, especially the cooling of the polymer melt, affect the morphology of thin-wall parts as discussed above. The morphological structure of the different manufactured specimens is shown in Figure 3. 


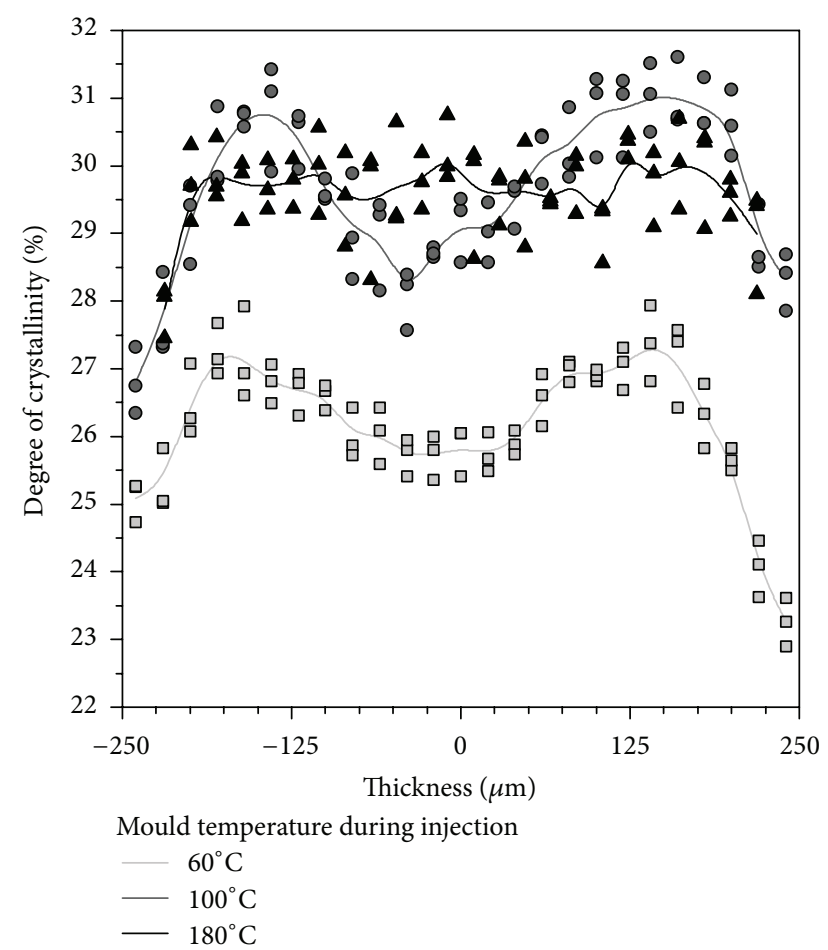

FIGURE 4: Degree of crystallinity over the cross section in dependence of process conditions.

A mould temperature of $60^{\circ} \mathrm{C}$ leads to a fast cooling of the material (especially in the surface area which has direct contact with the mould) already during the injection phase. This entails a significant amorphous-like surface layer and only small single spherulites in the core area. An increasing mould temperature of $100^{\circ} \mathrm{C}$ reduces the cooling velocity resulting in a smaller surface layer and an increasingly spherulitic morphology. The mould temperature of $180^{\circ} \mathrm{C}$ during injection results in an almost homogeneous morphology over the entire cross section. This is due to the reduced cooling velocity of the melt and the sufficient time for crystallization of the polymer. Only the surface area reveals a smaller spherulitic structure.

3.2. Crystallinity. Correlating with the influence on the morphology the different cooling conditions also affect the degree of crystallinity. The degree of crystallinity of the different manufactured specimens is shown in Figure 4. All the parts show a different gradient over the cross section, with a low degree in the surface area and an increasing value to the core area. Furthermore, the parts that had been injection moulded at a mould temperature of $60^{\circ} \mathrm{C}$ show a low degree of crystallinity over the complete cross section. Those parts injection moulded at higher mould temperatures show an increased degree of crystallinity. The degree of crystallinity is approximately $5 \%$ higher as in the parts injection moulded at $60^{\circ} \mathrm{C}$. In addition, a further increase of the mould temperature up to $180^{\circ} \mathrm{C}$ during the melt injection shows less effect on the degree of crystallinity. At a mould temperature of $100^{\circ} \mathrm{C}$ the degree of crystallinity reaches a depth of ca.

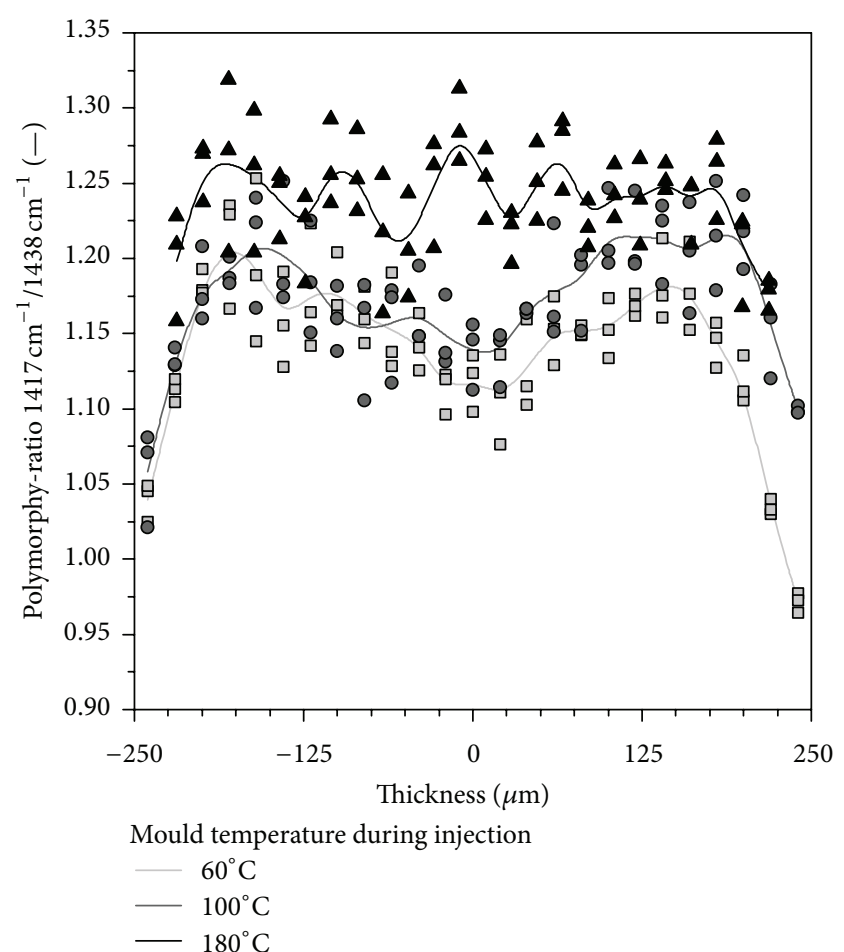

FIGURE 5: Polymorphy-ratio of the absorbance at a wavelength of $1417 \mathrm{~cm}^{-1}$ ( $\alpha$ modification) and $1438 \mathrm{~cm}^{-1}$ ( $\beta$ modification) over the cross section in dependence of process conditions.

$100 \mu \mathrm{m}$ from the surface, a maximum value, and decreases to the core. This is attributed to a shear induced nucleation (which favors the crystallization process) in the surface and a more thermal crystallization in the core and correlates with the results of other works [40,41]. A mould temperature of $180^{\circ} \mathrm{C}$ does not show such a difference in crystallinity across the thickness. These specimens reveal a nearly homogeneous degree of crystallinity over the cross section.

In Figure 5 the ratio of the absorbance bands of $1417 \mathrm{~cm}^{-1}$ to $1438 \mathrm{~cm}^{-1}$ (polymorphy-ratio) is illustrated over the cross section of the specimens. An increasing ratio suggests a higher fraction of $\alpha$ crystal modification due to a slower cooling rate. The values of the ratio of the specimens show a low value in the surface area and a higher ratio in the core area. Accordingly, due to the high cooling rate in the surface area the $\gamma$ modification is preferably formed at ca. $100 \mu \mathrm{m}$ from the surface. This correlates with the degree of crystallinity, which is also reduced in the surface area. Furthermore, the specimens injection moulded at $60^{\circ} \mathrm{C}$ and $100^{\circ} \mathrm{C}$ reveal a decreasing ratio in the core which also correlates with the degree of crystallinity.

The specimens injection moulded at $180^{\circ} \mathrm{C}$ have a higher polymorphy-ratio, thus a higher fraction of $\alpha$ crystals due to the slower cooling. Furthermore, these specimens show an almost constant ratio in the core and the difference of the ratio between core and surface is also reduced which correlates with the above discussed homogeneously morphological structure and the degree of crystallinity across the thickness. Consequently, based on defined process conditions, that is, 


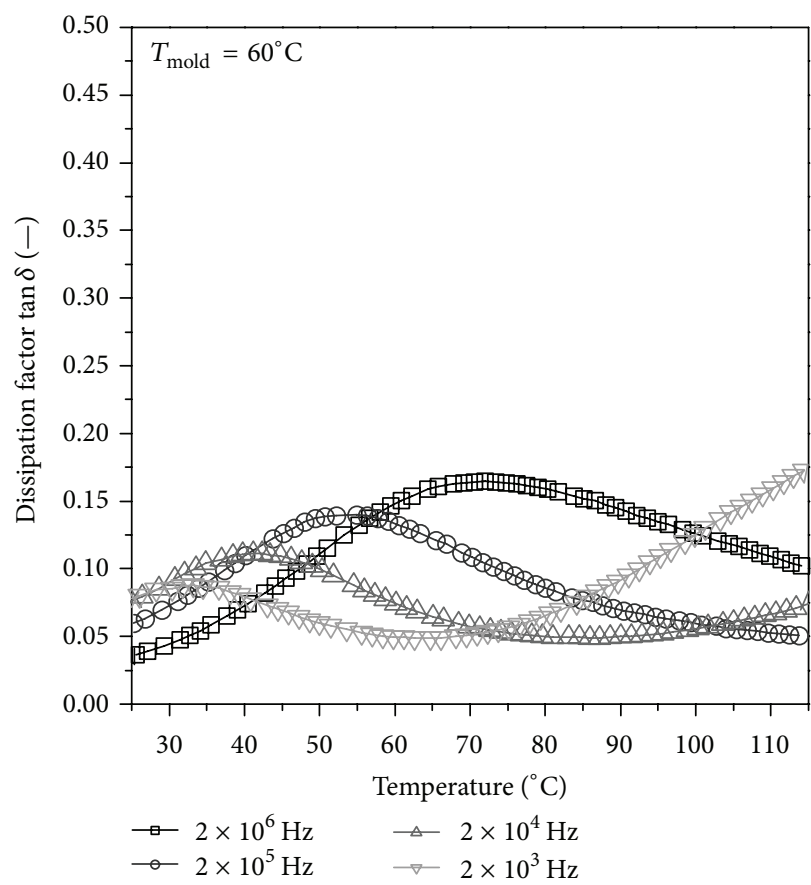

(a)

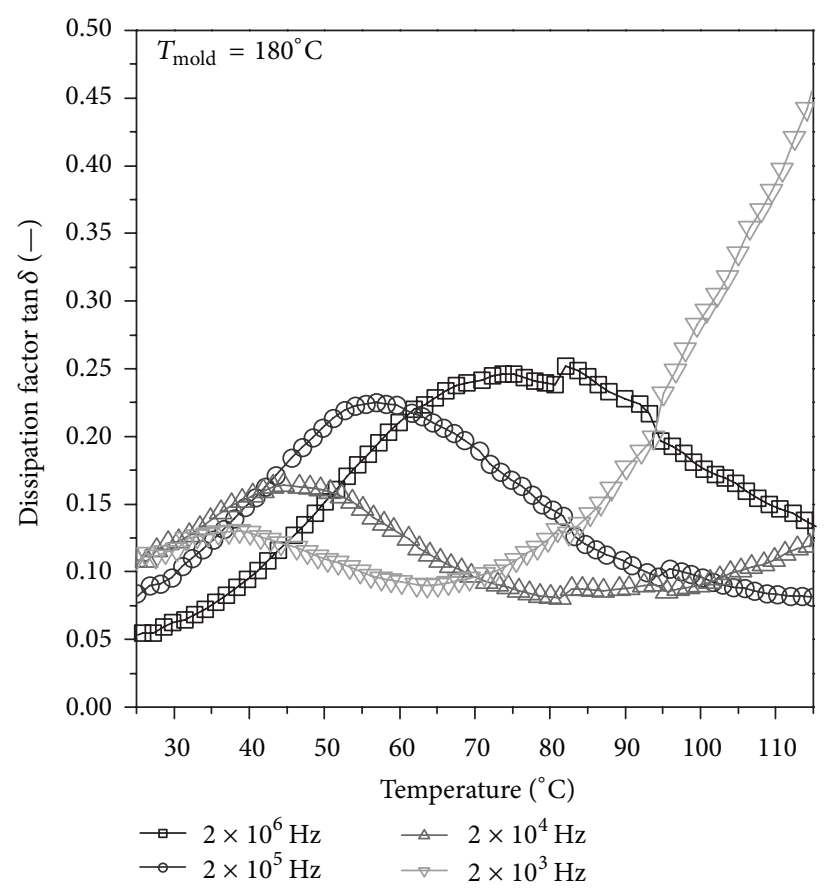

(b)

Figure 6: Dissipation factor $\tan \delta$ at varied frequencies for the specimens injection moulded at $60^{\circ} \mathrm{C}$ and $180^{\circ} \mathrm{C}$.

defined cooling conditions during processing, the molecular chains can reach a more compact packaging during crystallization. This allows a higher crystal perfection resulting in an increasing fraction of $\alpha$ crystals.

3.3. Dielectric Behaviour. Figure 6 shows the dissipation factor of the dielectric measurements of the PA66. The investigations are focused on the $\alpha$ relaxation; thus the temperature range of $20-120^{\circ} \mathrm{C}$ is of interest for the investigations. As expected, the $\alpha$ relaxation is affected by the frequency, in which a higher frequency shifts the relaxation to a higher temperature [35].

However, the measurements reveal that the process induced modified internal properties affect the dielectric behaviour of the material. The specimens with the favoured crystalline morphology reveal a shift of the dissipation factor to a higher value. This is due to a higher loss factor that means more energy is dissipated by the material for the relaxation process. This effect was already described [35]. Because of the higher degree of crystallinity and also the favoured crystalline structure (i.e., an increased $\alpha$ crystal modification) more energy is used to activate the relaxation process.

Figure 7 focuses on the peak temperature and the relaxation factor for the $\alpha$ relaxation. It reveals as mentioned above the shift of the relaxation temperature with increasing frequency. Furthermore, the process induced modified inner structure leads also to a shift of the temperature. The observed temperature shift amounts to more than $3 \mathrm{~K}$, but with increasing frequency the temperature shift diminishes which reflects the viscoelastic nature of polymers by obeying the time-temperature superposition principle [35].
The dissipation factor is also affected by the frequency and the internal structure. A higher frequency increases the dissipation factor, similar to the temperature shift. The influence of the inner structure, due to a reduced cooling rate, affects also the dissipation factor as mentioned above. The change in the process induced inner structure leads to $n$ approximately $50 \%$ higher dissipation factor independent of the applied frequency. Consequently, the dissipation factor correlates constantly with the degree and the modification of the crystalline properties. However, it is not possible with these results to separate stringently the influence of the amount of crystallinity and the crystalline modifications. Further investigations should reveal the influence of degree of crystallinity and crystalline modifications on the dielectric properties.

3.4. Translucence. Figure 8 shows the transmission of the material shown in dependence of the cooling conditions. The specimens obtain a transmission of $90 \%$ in the visible light area at the upper end. The degree of transmission decreases slightly with reduced wavelength. At the lower end of the visible light the light absorption increases and only 67 to $75 \%$ of the light is transmitted.

As expected, the specimen injection moulded at a low mould temperature shows a higher value of light transmittance as the specimens injection moulded at higher mould temperatures. This is due to the fact that the process induced higher degree of crystallinity and more spherulitic morphology (see Figure 3) as a result of the slower cooling rate. This correlates with the results of Kolesov et al. [25] for PA6 or other semicrystalline polymers [37, 38]. However, 


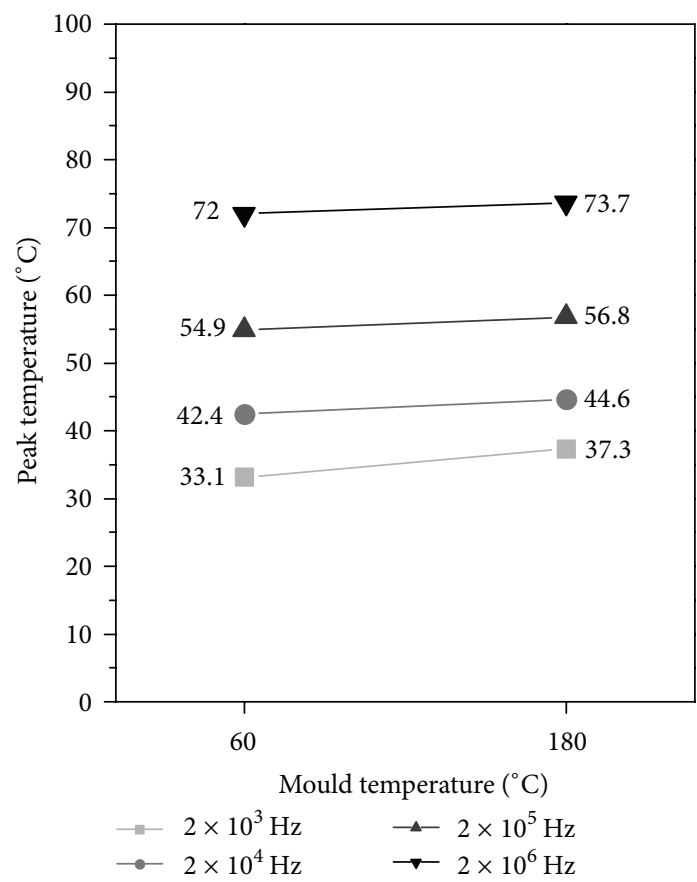

(a)

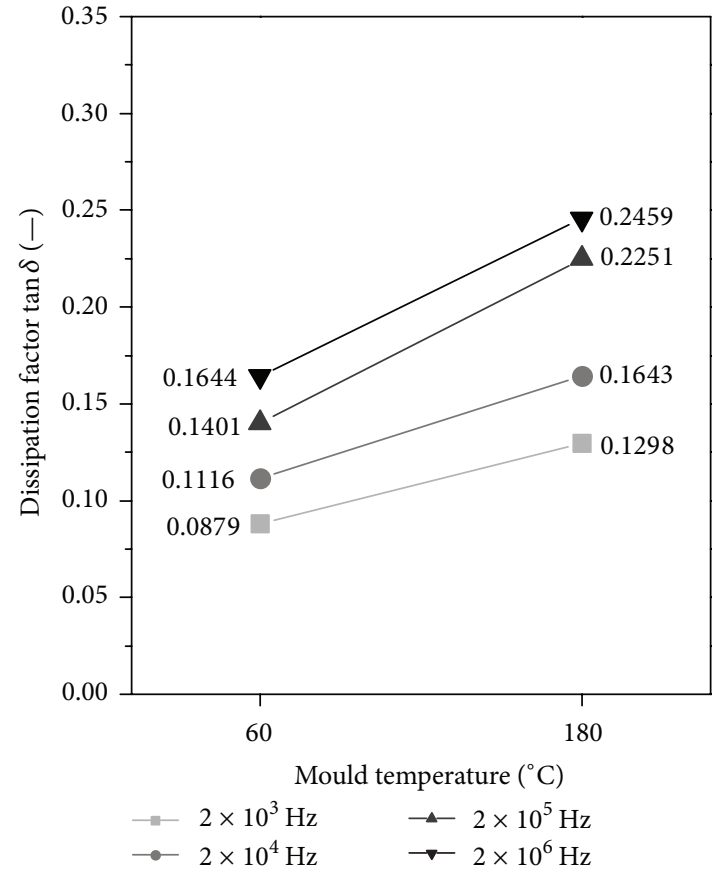

(b)

FIGURE 7: Peak temperature (left) and dissipation factor (right) of the $\alpha$ relaxation in dependence of frequency and process conditions.

the difference of light transmittance in the lower end of the visible light band seems to have little effect on the amount of perceived brightness, because this is mostly attributed to the light transmittance in the wavelength between 500 and $600 \mathrm{~nm}[42]$.

\section{Conclusions}

In micro- and thin-wall injection moulding the process conditions, especially the cooling conditions, have particularly great importance in the development of the internal structure during processing of thermoplastic polymers. Consequently, the properties in use are also influenced. The investigations in this paper discuss the influence of different process conditions exemplarily on PA66 on the formation of the inner structure of an injection moulded micropart and the resulting properties in use.

(1) A faster cooling of the polymer melt leads as expected to a modified morphology. A slow cooling, due to increased mould temperatures during injection, reduces or inhibits the development of a surface layer and allows a more homogeneous morphology. This also affects the degree of crystallinity which increases with a reduced cooling rate.

(2) Reduced cooling conditions favour also the development of crystalline modifications. In the case of the used PA66 more $\alpha$ crystals are formed by slow cooling. This was revealed by FTIR spectroscopy and correlates also with DETA measurements.
(3) The influence of the dielectric behaviour can be used for material analysis as for modifying part properties with regard to their applications.

(4) However, the influence of the inner structure can also affect the properties in use which was exemplarily shown on the light transmittance. The translucence can be reduced (or increased) with slow (or fast) cooling of the part due to a modified crystalline structure. But since the light transmittance is influenced below a wavelength of approximately $400 \mathrm{~nm}$, the effect on visible translucence will be rather small for the applied polymer. However, this effect has to be investigated in further studies.

Future investigation should also reveal more in detail the relationship between process conditions, the developed inner structures, and the resulting part properties. Particularly, correlations with static and dynamic mechanical properties and the effect of physical or chemical ageing are of interest, as well as the transfer to other polymers.

\section{Conflict of Interests}

The authors declare that there is no conflict of interests regarding the publication of this paper.

\section{Acknowledgments}

The authors would like to thank the Bavarian Research Foundation for funding this work. The authors also extend their gratitude to their industrial partners Werkzeugbau Hofmann 


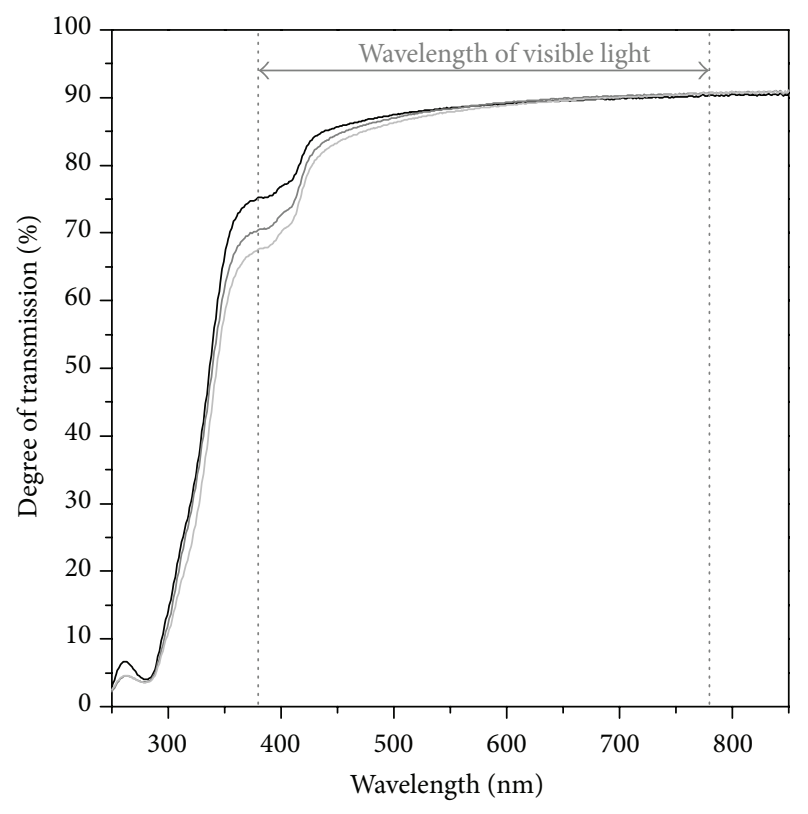

Mould temperature during injection

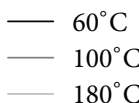

Figure 8: Normalized light transmission of the specimens in dependence of cooling conditions as function of the wavelength.

GmbH, Oechsler AG, Single Temperiertechnik GmbH, hotec $\mathrm{GmbH}$, Arburg GmbH \& Co. KG, and BASF SE for providing the equipment and material. The authors also acknowledge TA Instruments for carrying out DETA measurements and Mrs. Pia Trawiel for her helpful discussions.

\section{References}

[1] A. K. Angelov and J. P. Coulter, "Micromolding product manufacture: a progress report," in Proceedings of the Annual Technical Conference (ANTEC '04), pp. 748-751, Chicago, Ill, USA, May 2004.

[2] D. M. Bibber, "Micro molding challenges," in Proceedings of the SPE Annual Technical Conference (ANTEC '04), pp. 3703-3711, Chicago, Ill, USA, 2004.

[3] O. Pfirrmann and M. Astor, Trendreport MikrosystemtechnikInnovative Ideen rund um die Mikrosystemtechnik, PrognosAG, Basel, Switzerland, 2006.

[4] R. Pantani, L. Balzano, and G. W. M. Peters, "Flow-induced morphology of iPP solidified in a shear device," Macromolecular Materials and Engineering, vol. 297, no. 1, pp. 60-67, 2012.

[5] A. M. Tom, G. S. Layser, and J. P. Coulter, "Mechanical property determination of micro injection molded tensile test specimens," in Proceedings of the SPE Annual Technical Conference (ANTEC '06), pp. 2541-2545, Charlotte, NC, USA, May 2006.

[6] T. Nguyen-Chung, C. Löser, G. Jüttner, M. Obadal, T. Pham, and M. Gehde, "Morphology analysis of injection molded micro-parts," Journal of Plastics Technology, no. 3, pp. 86-114, 2011.

[7] S. Meister and D. Drummer, "Influence of manufacturing conditions on measurement of mechanical material properties on thermoplastic micro tensile bars," Polymer Testing, vol. 32, no. 2, pp. 432-437, 2013.

[8] S. Meister, A. Jungmeier, and D. Drummer, "Long-term properties of injection-molded micro-parts: influence of part dimensions and cooling conditions on aging behavior," Macromolecular Materials and Engineering, vol. 297, no. 10, pp. 994-1004, 2012.

[9] S. Meister and D. Drummer, "Affecting the ageing behaviour of injection-moulded microparts using variothermal mould tempering," Advances in Mechanical Engineering, vol. 2013, Article ID 407964, 7 pages, 2013.

[10] S. Meister and D. Drummer, "Dimension-dependent long-term properties of injection molded micro parts," in Proceedings of the SPE Technical Conference \& Exhibition (ANTEC '14), Las Vegas, Nev, USA, 2014.

[11] D. Schmiederer and E. Schmachtenberg, "Einfluesse auf die Eigenschaften kleiner und duennwandiger Spritzgussteile," Zeitschrift Kunststofftechnik, vol. 2, no. 5, pp. 1-21, 2011.

[12] A. Lurz and E. Schmachtenberg, "Influences on the properties of small and thin-walled injection molded parts-part 2: importance of the thermal conductivity of the mold material," Journal of Plastics Technology, vol. 4, no. 1, pp. 1-18, 2008.

[13] T. Walter, W. Schinkoethe, W. Ehrfeld, C. Schaumburg, and L. Weber, "Injection moulding of microstructures with inductive mould heating," in Proceedings of the 16th Stuttgarter KunststoffKolloquium, pp. 1-10, Stuttgart, Germany, 1999.

[14] J. Giessauf, G. Pillwein, and G. Steinbichler, "Variotherm temperature control is fit for production," Kunststoffe International, vol. 98 , no. 8, pp. 57-62, 2008.

[15] D. Drummer, K. Gruber, and S. Meister, "Alternating temperature technology controls parts properties," Kunststoffe International, vol. 101, no. 4, pp. 25-27, 2011.

[16] E. Haberstroh and M. Brandt, "Determination of mechanical properties of thermoplastics suitable for micro systems," Macromolecular Materials and Engineering, vol. 287, no. 12, pp. 881888, 2002.

[17] D. Drummer, A. Seefried, and S. Meister, "Characterization of material stiffness on injection moulded microspecimens using different test methods," Advances in Materials Science and Engineering, vol. 2014, Article ID 769206, 8 pages, 2014.

[18] T. Koch and S. Seidler, "Mechanical properties of microinjection moulded components," Macromolecular Symposia, vol. 181, no. 1, pp. 499-506, 2002.

[19] G. R. Greenway, P. S. Allan, and P. R. Hornsby, "The characterisation and physical testing of micro-mouldings," in Proceedings of the 61st Annual Technical Conference (ANTEC '03), pp. 19951999, Nashville, Tenn, USA, May 2003.

[20] A. Jungmeier, D. Drummer, and G. W. Ehrenstein, "Optimization strategies for micro parts," Kunststoffe International, vol. 101, no. 7, pp. 50-53, 2011.

[21] M. I. Kohan, Nylon Plastics Handbook, Hanser, Munich, Germany, 1995.

[22] H. Batzer, Polymere Werkstoffe I: Chemie und Physik, Thieme, Stuttgart, Germany, 1985.

[23] H. W. Starkweather, J. F. Whitney, and D. R. Johnson, "Crystalline order in nylon 66," Journal of Polymer Science A: General Papers, vol. 1, no. 2, pp. 715-723, 1963.

[24] H.-J. Radusch, M. Stolp, and R. Androsch, "Structure and temperature-induced structural changes of various polyamides," Polymer, vol. 35, no. 16, pp. 3568-3571, 1994. 
[25] I. Kolesov, D. Mileva, and R. Androsch, "Mechanical behavior and optical transparency of polyamide 6 of different morphology formed by variation of the pathway of crystallization," Polymer Bulletin, vol. 71, no. 3, pp. 581-593, 2014.

[26] H. Hama and K. Tashiro, "Structural changes in non-isothermal crystallization process of melt-cooled polyoxymethylene. [I] Detection of infrared bands characteristic of folded and extended chain crystal morphologies and extraction of a lamellar stacking model," Polymer, vol. 44, no. 10, pp. 3107-3116, 2003.

[27] B. Wu, Y. Gong, and G. Yang, "Non-isothermal crystallization of polyamide 6 matrix in all-polyamide composites: crystallization kinetic, melting behavior, and crystal morphology," Journal of Materials Science, vol. 46, no. 15, pp. 5184-5191, 2011.

[28] A. Xenopoulos and B. Wunderlich, "Conformational motion and disorder in aliphatic nylons the case of nylon 6.6," Colloid \& Polymer Science, vol. 269, no. 4, pp. 375-391, 1991.

[29] D. Galimberti, C. Quarti, A. Milani, L. Brambilla, B. Civalleri, and C. Castiglioni, "IR spectroscopy of crystalline polymers from ab initio calculations: Nylon 6,6," Vibrational Spectroscopy, vol. 66, pp. 83-92, 2013.

[30] A. J. Bur, "Dielectric properties of polymers at microwave frequencies: a review," Polymer, vol. 26, no. 7, pp. 963-977, 1985.

[31] T. W. Giants, "Crystallinity and dielectric properties of PEEK, poly(ether ether ketone)," Dielectrics and Electrical Insulation, vol. 1, no. 6, pp. 991-999, 1994.

[32] H. L. Zhang, N. S. Ong, and Y. C. Lam, "Experimental investigation of key parameters on the effects of cavity surface roughness in microinjection molding," Polymer Engineering and Science, vol. 48, no. 3, pp. 490-495, 2008.

[33] J. Betzabe Gonzalez-Campos, Z. Y. Garcia-Carvajal, E. Prokhorov et al., "Revisiting the thermal relaxations of poly(vinyl alcohol)," Journal of Applied Polymer Science, vol. 125, no. 5, pp. 4082-4090, 2012.

[34] K. Shinyama, T. Oi, and S. Fujita, "Dielectric relaxation phenomena of polylactic acid with $\beta$-crystalline chitin," International Journal of Polymer Science, vol. 2012, Article ID 389491, 5 pages, 2012.

[35] H. Nuriel, N. Kozlovich, Y. Feldman, and G. Marom, "Dielectric properties of nylon 6,6/aramid fibre microcomposites in the presence of transcrystallinity," Composites Part A: Applied Science and Manufacturing, vol. 31, no. 1, pp. 69-78, 2000.

[36] S. Meister and D. Drummer, "Influence of mold temperature on mold filling behavior and part properties in micro injection molding," International Polymer Processing, vol. 28, no. 5, pp. 550-557, 2013.

[37] R. S. Stein and R. Prud'Homme, "Origin of polyethylene transparency," Journal of Polymer Science Part B: Polymer Letters, vol. 9 , no. 8, pp. 595-598, 1971.

[38] J. H. Bheda and J. E. Spruiell, "The effect of process and polymer variables on the light transmission properties of polypropylene tubular blown films," Polymer Engineering and Science, vol. 26, no. 11, pp. 736-745, 1986.

[39] A. Jungmeier, Structure and properties of injection moulded thermoplastic micro-parts [Ph.D. thesis], University ErlangenNuremberg, 2010.

[40] H. Janeschitz-Kriegl and E. Ratajski, "Kinetics of polymer crystallization under processing conditions: transformation of dormant nuclei by the action of flow," Polymer, vol. 46, no. 11, pp. 3856-3870, 2005.
[41] A. Jungmeier, K. Vetter, and G. W. Ehrenstein, "Thermally low conductive moulds for micro injection moulding of thermoplastics," in Proceedings of the International Conference MultiMaterial Micro-Manufacture (4M/ICOMM '09), pp. 91-94, Karlsruhe, Germany, 2009.

[42] M. Bass, C. Cusatis, J. Enoch et al., Handbook of Optics III: Vision and Vision Optics, McGraw-Hill Professional, 3rd edition, 2009. 

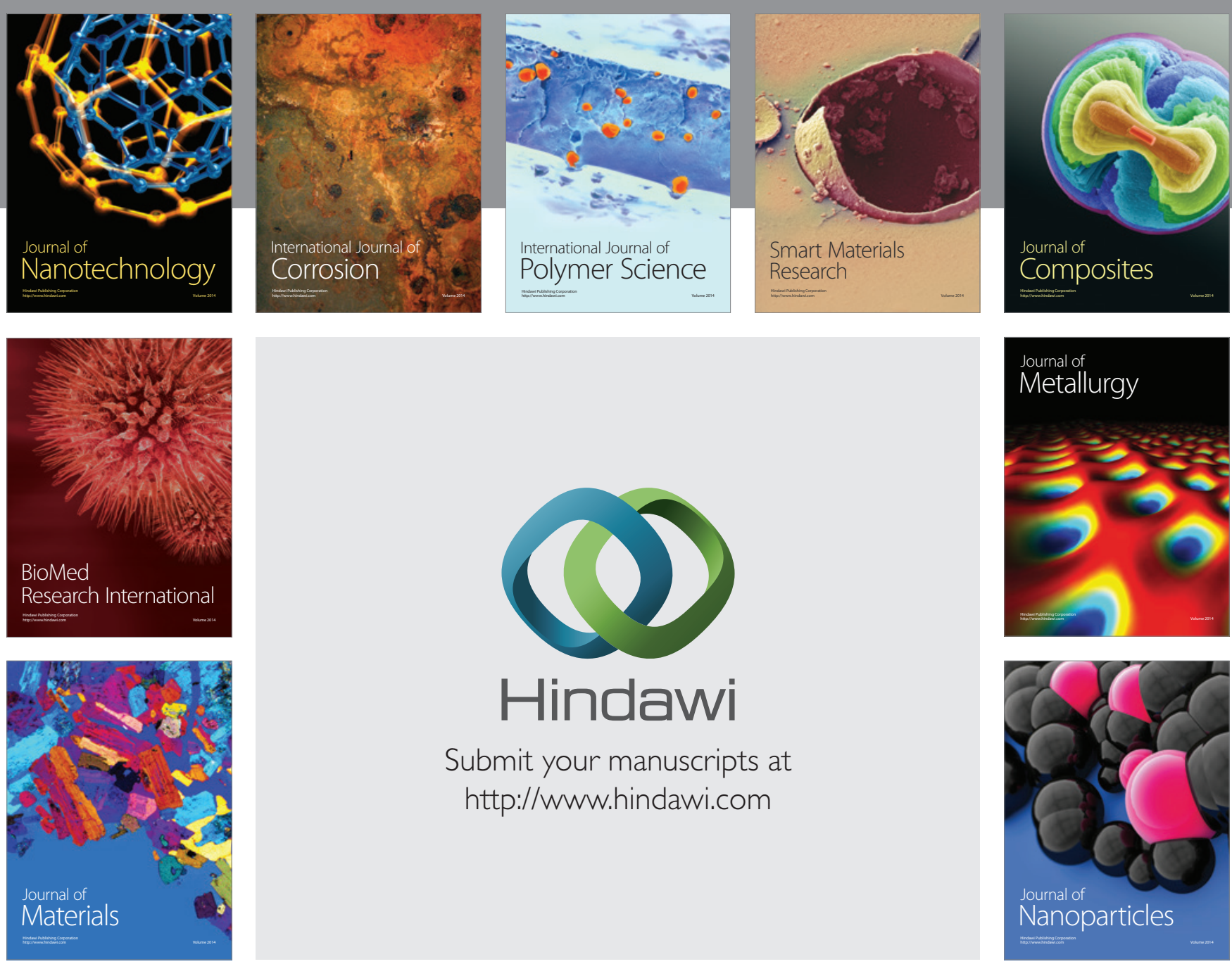

Submit your manuscripts at http://www.hindawi.com
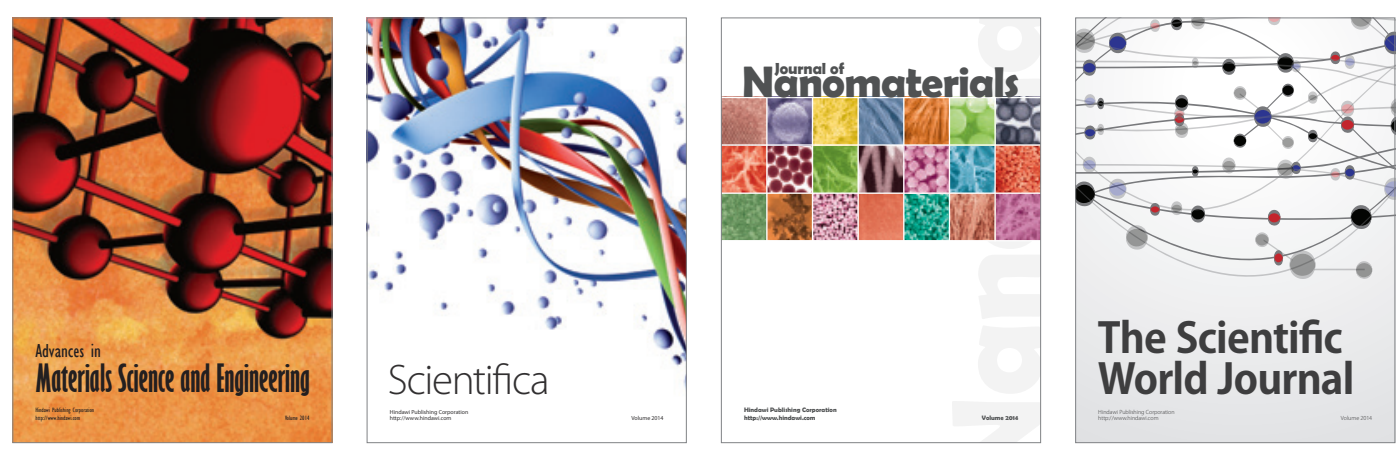

\section{The Scientific World Journal}
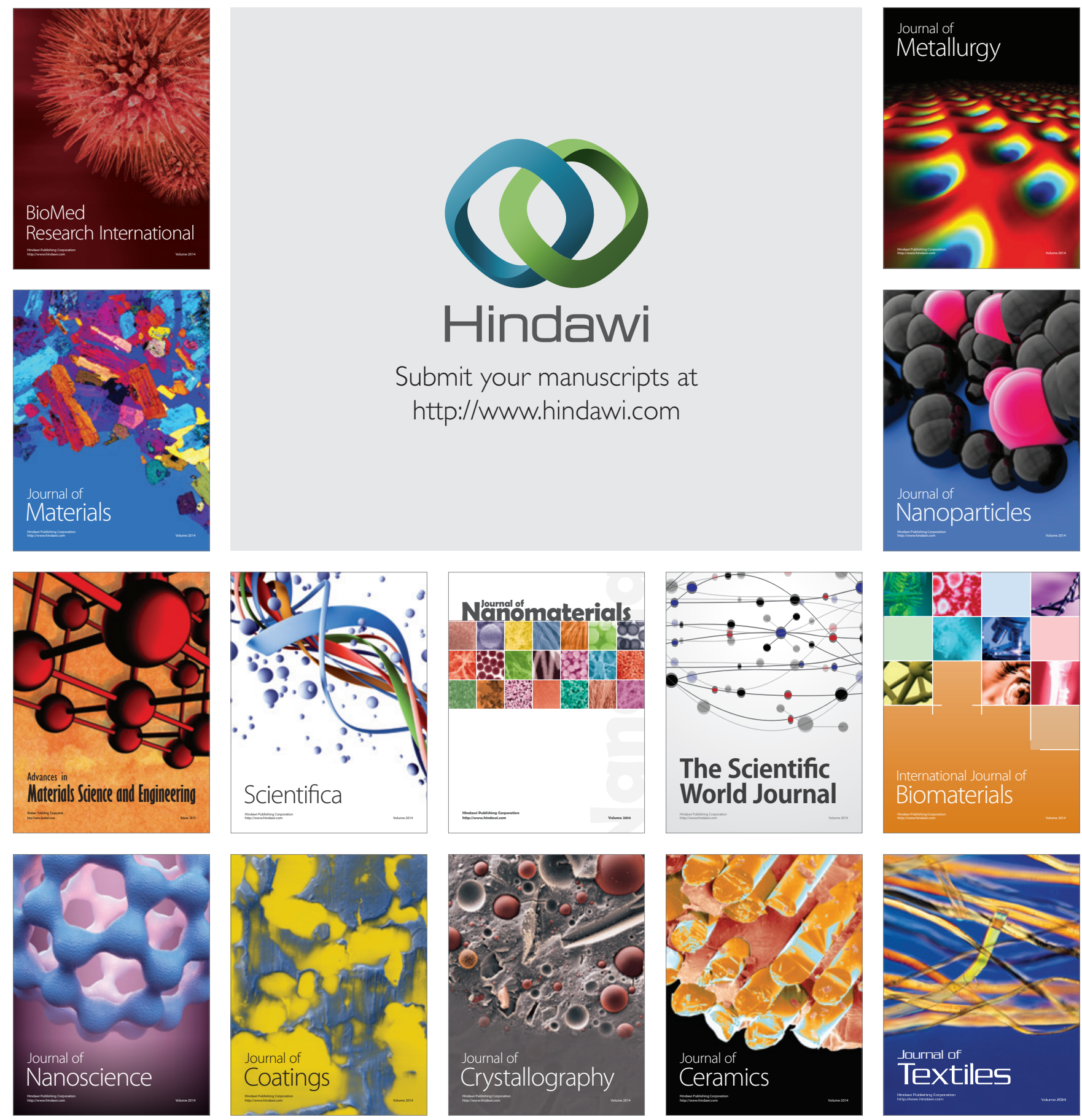